\title{
Accuracy of various criteria for lymph node staging in ductal adenocarcinoma of the pancreatic head by computed tomography and magnetic resonance imaging
}

Florian N. Loch ${ }^{1 *}$ (D) Patrick Asbach², Matthias Haas², Hendrik Seeliger ${ }^{1}$, Katharina Beyer ${ }^{1}$, Christian Schineis ${ }^{1}$, Claudius E. Degro', Georgios A. Margonis ${ }^{3}$, Martin E. Kreis ${ }^{1}$ and Carsten Kamphues ${ }^{1}$

\begin{abstract}
Background: Lymph node staging of ductal adenocarcinoma of the pancreatic head (PDAC) by cross-sectional imaging is limited. The aim of this study was to determine the diagnostic accuracy of expanded criteria in nodal staging in PDAC patients.

Methods: Sixty-six patients with histologically confirmed PDAC that underwent primary surgery were included in this retrospective IRB-approved study. Cross-sectional imaging studies (CT and/or MRI) were evaluated by a radiologist blinded to histopathology. Number and size of lymph nodes were measured (short-axis diameter) and characterized in terms of expanded morphological criteria of border contour (spiculated, lobulated, and indistinct) and texture (homogeneous or inhomogeneous). Sensitivities and specificities were calculated with histopathology as a reference standard.
\end{abstract}

Results: Forty-eight of 66 patients (80\%) had histologically confirmed lymph node metastases (pN+). Sensitivity, specificity, and Youden's Index for the criterion "size" were 44.2\%, 82.4\%, and 0.27; for "inhomogeneous signal intensity" 25.6\%, 94.1\%, and 0.20; and for "border contour" 62.7\%, 52.9\%, and 0.16, respectively. There was a significant association between the number of visible lymph nodes on preoperative $C T$ and lymph node involvement ( $p N+, p=0.031$ ).

Conclusion: Lymph node staging in PDAC is mainly limited due to low sensitivity for detection of metastatic disease. Using expanded morphological criteria instead of size did not improve regional nodal staging due to sensitivity remaining low. Combining specific criteria yields improved sensitivity with specificity and PPV remaining high.

Keywords: Ductal adenocarcinoma of the pancreatic head, Staging, Lymph nodes, Computed tomography, Magnetic resonance imaging, Cross-sectional imaging, Neoadjuvant therapy

\footnotetext{
* Correspondence: Florian.Loch@charite.de

${ }^{1}$ Charité - Universitätsmedizin Berlin, corporate member of Freie Universität Berlin, Humboldt-Universität zu Berlin, and Berlin Institute of Health,

Department of Surgery, Campus Benjamin Franklin, Hindenburgdamm 30,

12203 Berlin, Germany

Full list of author information is available at the end of the article
}

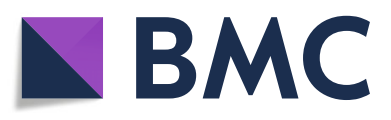

(- The Author(s). 2020 Open Access This article is licensed under a Creative Commons Attribution 4.0 International License, which permits use, sharing, adaptation, distribution and reproduction in any medium or format, as long as you give appropriate credit to the original author(s) and the source, provide a link to the Creative Commons licence, and indicate if changes were made. The images or other third party material in this article are included in the article's Creative Commons licence, unless indicated otherwise in a credit line to the material. If material is not included in the article's Creative Commons licence and your intended use is not permitted by statutory regulation or exceeds the permitted use, you will need to obtain permission directly from the copyright holder. To view a copy of this licence, visit http://creativecommons.org/licenses/by/4.0/ The Creative Commons Public Domain Dedication waiver (http://creativecommons.org/publicdomain/zero/1.0/) applies to the data made available in this article, unless otherwise stated in a credit line to the data. 


\section{Background}

Pancreatic cancer remains one of the most lethal malignancies being the fourth leading cause of cancer death in the USA and predicted to be the second leading cause of cancer death by 2020 [1]. The overall 5 -year survival after diagnosis is 7\% [2], and at the time of diagnosis, the main proportion of patients has advanced-stage disease leaving only $15-20 \%$ qualified for resective surgery [3]. Pancreatic cancer is located in the head of the pancreas in $75 \%$ of the cases [4]. Even after successful resective surgery in patients with cancer of the pancreatic head, the 5-year survival remains as low as $21 \%$ [5]. These data underline the importance of establishing multimodal therapeutic concepts for patients with pancreatic cancer as per other entities of abdominal cancer.

Apart from the potential to increase the resectability rate of pancreatic cancer by neoadjuvant therapy $[6,7]$, there is evidence that patients which are successfully downstaged from node-positive disease (cN1) to nodenegative disease (ypN0) prior to surgery benefit in terms of higher 5-year survival rate [8]. This would qualify nodal involvement as a sufficient basis for indicating neoadjuvant therapy. Yet, even given advanced imaging technologies, identifying lymph node metastasis remains challenging. Consequently, the indication of a potentially effective neoadjuvant therapy $(\mathrm{cN}+)$ with side effects in lymph node-positive patients $(\mathrm{cN}+)$ is mainly based on unreliable clinical staging.

The established criterion for lymph node involvement in pancreatic cancer is size. Using the size underlies the assumption that tumor spread to regional lymph nodes leads to an enlargement of the respective lymph node. The usual cut-off value is a shortaxis diameter of $10 \mathrm{~mm}$ [3, 9-12]. It has been shown though that lymph nodes of $\geq 10 \mathrm{~mm}$ are not seen more frequently in patients with histopathological lymph node involvement $(\mathrm{pN}+)$ [13]. In various other tumor entities, expanded morphological criteria such as texture and border contour of lymph nodes are used for the assessment of lymph node malignancy on both computed tomography (CT) and magnetic resonance (MR) imaging. This is utilized in order to improve the accuracy of lymph node staging [14-16]. By applying morphological criteria instead of Brown et al. size criterion alone, the sensitivity was improved from 42 to $85 \%$ and the specificity from 87 to $97 \%$ in lymph node staging of rectal cancer [16].

Thus, the aim of this study was to determine the accuracy of lymph node staging in patients with ductal adenocarcinoma of the pancreatic head by both computed tomography and magnetic resonance imaging using size and expanded morphological criteria.

\section{Material and methods \\ Patients}

In this retrospective single-center study approved by the local ethics committee, consecutive patients with histologically proven ductal adenocarcinoma of the pancreatic head that underwent primary surgery between February 2013 and November 2018 at the Department of Surgery, Campus Benjamin Franklin, Charité-University Medicine Berlin, Germany, were included. Patients were retrieved from the database of our pancreatic cancer center certified by the German Cancer Society $(n=80)$. Inclusion criteria were primary oncologic tumor resection and the presence of preoperative cross-sectional imaging of sufficient quality (see below). Exclusion criteria were neoadjuvant therapy, presence of a potential simultaneous cause of lymphadenopathy of the upper abdominal region (e.g. abdominal lymphoma, neuroendocrine tumor), and main tumor mass located outside the pancreatic head on histopathology. The process of patient selection with the respective reasons for inclusion and exclusion is shown in Fig. 1.

\section{Cross-sectional imaging}

All images were retrospectively analyzed for the purpose of this study by a single abdominal radiologist, with more than 12 years of experience in staging of tumors of the visceral organs, blinded to the results of histopathology.

All cross-sectional imaging studies were assessed for sufficient image quality by the radiologist prior to commencement. For $\mathrm{CT}$ imaging, the minimum quality was defined as either thin-section CT $(\leq 2 \mathrm{~mm}$ reconstructed slice thickness) or contrast-enhanced CT with a slice thickness of $\leq 5 \mathrm{~mm}$. For MRI, minimum quality was defined as availability of an axial T2-weighted sequence with fat suppression (slice thickness $\leq 5 \mathrm{~mm}$ ) in combination with a venous phase post-contrast 3D gradientecho sequence (slice thickness $\leq 3 \mathrm{~mm}$ ).

For lymph node assessment, all visible regional lymph nodes in the field of view were recorded on a score chart and the total number of visible lymph nodes per patient was calculated. Then, for each patient, all lymph nodes were characterized in terms of size (long- and short-axis diameter in millimeters) and the expanded morphological criteria border contour (lobulated, spiculated, indistinct, or unaltered) and texture (homogeneous or inhomogeneous, Fig. 2 based on Kim et al. [17]).

Regional lymph nodes of the pancreas are defined as the following lymph node station numbers: $5,6,7,8 \mathrm{a}$, $8 \mathrm{p}, 9,10,11 \mathrm{p}, 11 \mathrm{~d}, 12 \mathrm{a}, 12 \mathrm{~b}, 12 \mathrm{p}, 13 \mathrm{a}, 13 \mathrm{~b}, 14 \mathrm{p}, 14 \mathrm{~d}, 17 \mathrm{a}$, $17 \mathrm{~b}$, and 18 [17]. In all cases in which a lymph node was not definitively regional, correlation with postoperative cross-sectional imaging was performed to assess whether the lymph node was resected or not. Only resected lymph nodes were analyzed in this study. 


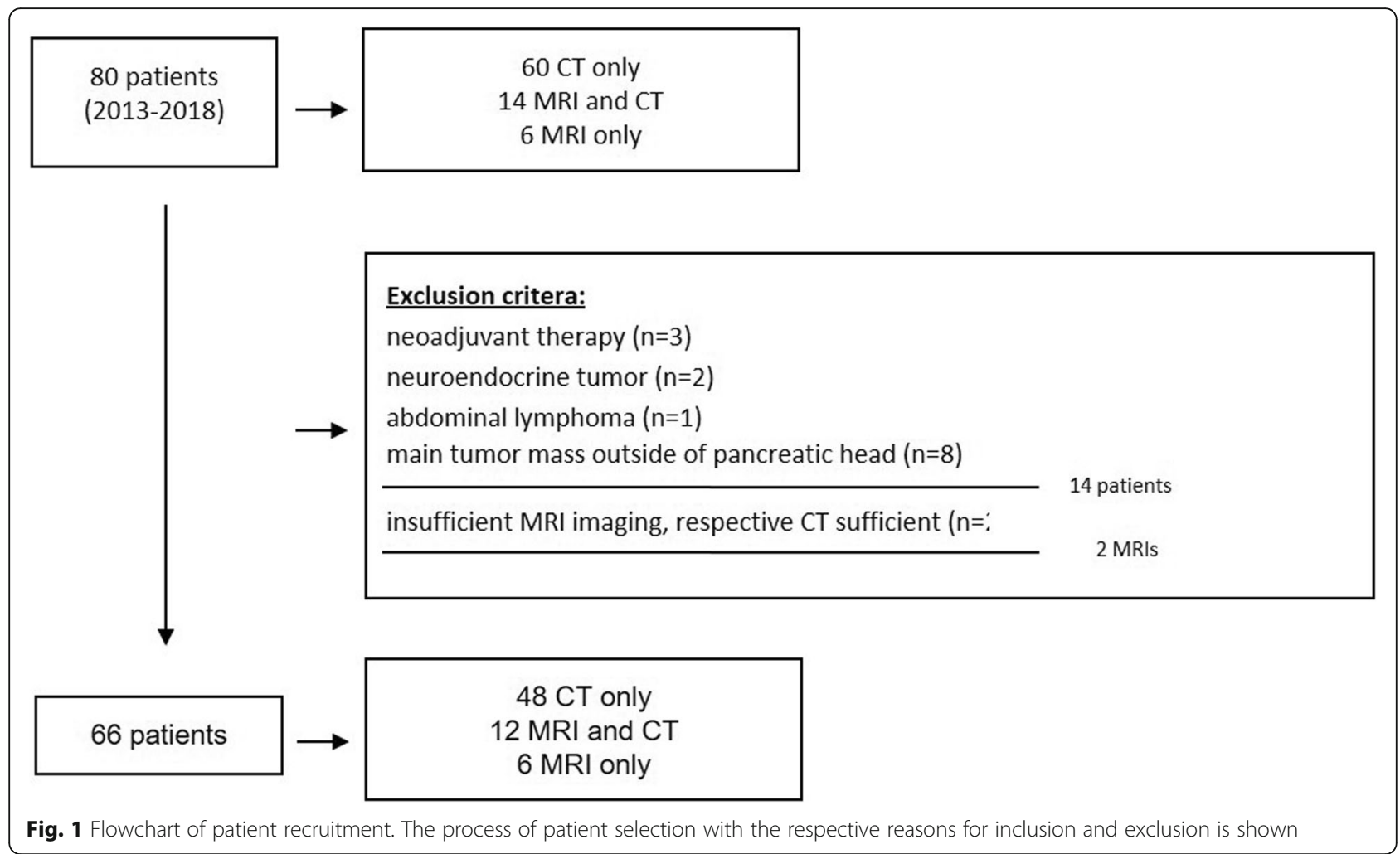

A second radiologist with more than 5 years of experience in staging of tumors of the visceral organs, also blinded to the results of histopathology, evaluated the CT examinations of a representative subgroup of 20 patients for evaluation of interobserver agreement.

\section{Surgery}

All patients underwent primary, oncologic pyloruspreserving pancreaticoduodenectomy or Whipple procedure with complete lymphadenectomy of the regional lymph nodes mentioned above.

\section{Histopathology}

For the study, the original histopathological reports using formalin-embedded surgical specimens were reviewed. Cancer of the pancreatic head was defined as a malignant tumor located within the pancreas to the right of the superior mesenteric vein and portal vein. Each patient with histologically proven lymph node metastases was classified as node-positive $(\mathrm{pN}+)$ regardless of the number of metastatic lymph nodes. Patients without any metastatic lymph nodes were classified as node-negative (pN-). The ratio of metastatic lymph nodes vs. the total number of retrieved lymph nodes was documented in

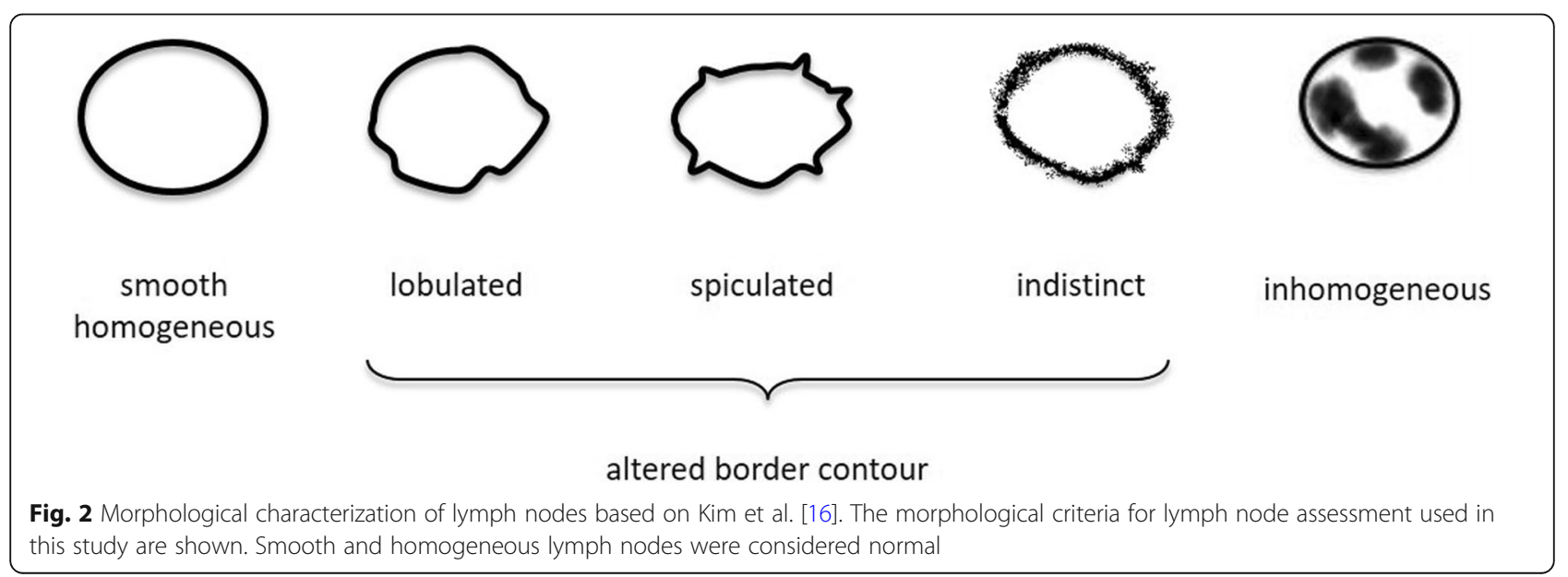


the histopathological report (e.g., 0/14 or 3/23). Tumors were classified according to their respective TNM stage using the 8th Edition of TNM Classification of Malignant Tumors [18].

\section{Comparison of cross-sectional imaging and histopathology}

Sensitivity, specificity, and positive predictive value of the nodal status using CT and MRI, with histopathology as a reference standard, were calculated for lymph node involvement using size and morphological criteria. Specifically, nodal involvement criteria were based on either size (short-axis diameter), altered border contour (lobulated, spiculated or indistinct), and inhomogeneous signal intensity (Fig. 2). CT and MRI examinations were considered node-positive $(\mathrm{cN}+)$, if at least one lymph node met one of the respective criteria used for involvement. If no lymph node with the respective criteria was seen on CT or MRI, then the examination was considered node-negative (cN-).

\section{Statistical analysis}

Sensitivities, specificities, and positive predictive value (PPV) for the size criterion, and all morphological criteria were calculated for their respective cut-off values. An index summarizing the sensitivity and specificity for Youden's Index was calculated (Sensitivity + Specificity - 1) [19]. The number of lymph nodes visible on CT and MR images in the group with $(\mathrm{pN}+)$ and without $(\mathrm{pN}-)$ nodal metastases was compared using the MannWhitney $\mathrm{U}$ test. When calculating the association between CT and MRI criteria and lymph node positivity, the $\mathrm{x}$ 2-test was used. Interobserver agreement was calculated using Cohen's Kappa statistic. A p value of $\leq 0.05$ was considered to indicate a statistically significant difference.

\section{Results}

\section{Patients}

Sixty-six patients were included in the study (Fig. 1) with the characteristics of the patients presented in Table 1. Sixty of these patients were staged by preoperative CT, twelve of which had additional staging by MRI, and six patients were staged by only MRI. In two patients, the MRI examinations were excluded due to insufficient imaging quality. Both patients had sufficient staging by $\mathrm{CT}$ and were therefore included in the study. Of the 66 patients, 10 patients received preoperative biliary drainage. Eight of them were staged by CT only and two by MRI only.

\section{Computed tomography (CT)}

Lymph nodes were detected by CT in $96.7 \%$ (58/60) of the patients. The median number of visible lymph nodes
Table 1 Demographic data of patients with ductal adenocarcinoma of the pancreatic head undergoing primary tumor resection

\begin{tabular}{ll}
\hline Patients & $\mathrm{n}=66$ \\
\hline Age & 73 \\
Median age (years) & $44-86$ \\
Age range (years) & \\
Sex & $28(42 \%)$ \\
Female & $38(58 \%)$ \\
Male & \\
Cross-sectional imaging & $48(73 \%)$ \\
CT only & $12(18 \%)$ \\
CT and MRI & $6(9 \%)$ \\
MRI only & \\
Histopathological staging & $48(73 \%)$ \\
pN+ & $18(27 \%)$ \\
pN- & $5(8 \%)$ \\
PT1 & $39(59 \%)$ \\
PT2 & $22(33 \%)$ \\
pT3 &
\end{tabular}

was 5 (range $0-15$ ). The smallest visible lymph node was $2.0 \mathrm{~mm}$ of size whereas the largest measured $18 \mathrm{~mm}$ (short-axis diameter). The mean time between $\mathrm{CT}$ and surgery was 7 days with a median of 6 days (range 1-43). The slice thickness in 61 of the $66 \mathrm{CT}$ examinations (92.4\%) was $3 \mathrm{~mm}$ or less. In five CT examinations (7.6\%), slice thickness was $5 \mathrm{~mm}$.

\section{Size criterion for lymph node involvement on preoperative CT}

Figure 3 shows the percentage of patients with $(\mathrm{pN}+)$ and without $(\mathrm{pN}-)$ lymph node metastases in which a lymph node of the respective size was visible (5-11 $\mathrm{mm}$ ). In Table 2, sensitivity, specificity, and Youden's Index are presented for the respective cut-off values. Lymph nodes of small and medium size $(5-9 \mathrm{~mm})$ were visible in patients with $(51-95 \% ; 22-41 / 43, \mathrm{pN}+)$ and without lymph node metastases $(41-100 \% ; 7-17 / 17, \mathrm{pN}-)$ in even frequency. Large lymph nodes $(10-11 \mathrm{~mm})$ were seen more frequently in the lymph node-positive group (35-44\%; 15-19/43, pN+) than in the lymph nodenegative group $(12-18 \% ; 2-3 / 17, \mathrm{pN}-)$. The maximum value of Youden's Index for the size criterion was $\mathrm{J}=$ 0.27 (95\% CI; $0.00,0.45)$ when a cut-off value of $10 \mathrm{~mm}$ was applied, yielding a sensitivity of $44 \%$ and specificity of $82 \%$. Additionally, the presence of lymph nodes greater than $10 \mathrm{~mm}$ on preoperative $\mathrm{CT}$, and the histopathological confirmation of a lymph node metastasis $(\mathrm{pN}+)$, showed a trend towards significance $(\mathrm{p}=0.076)$. 


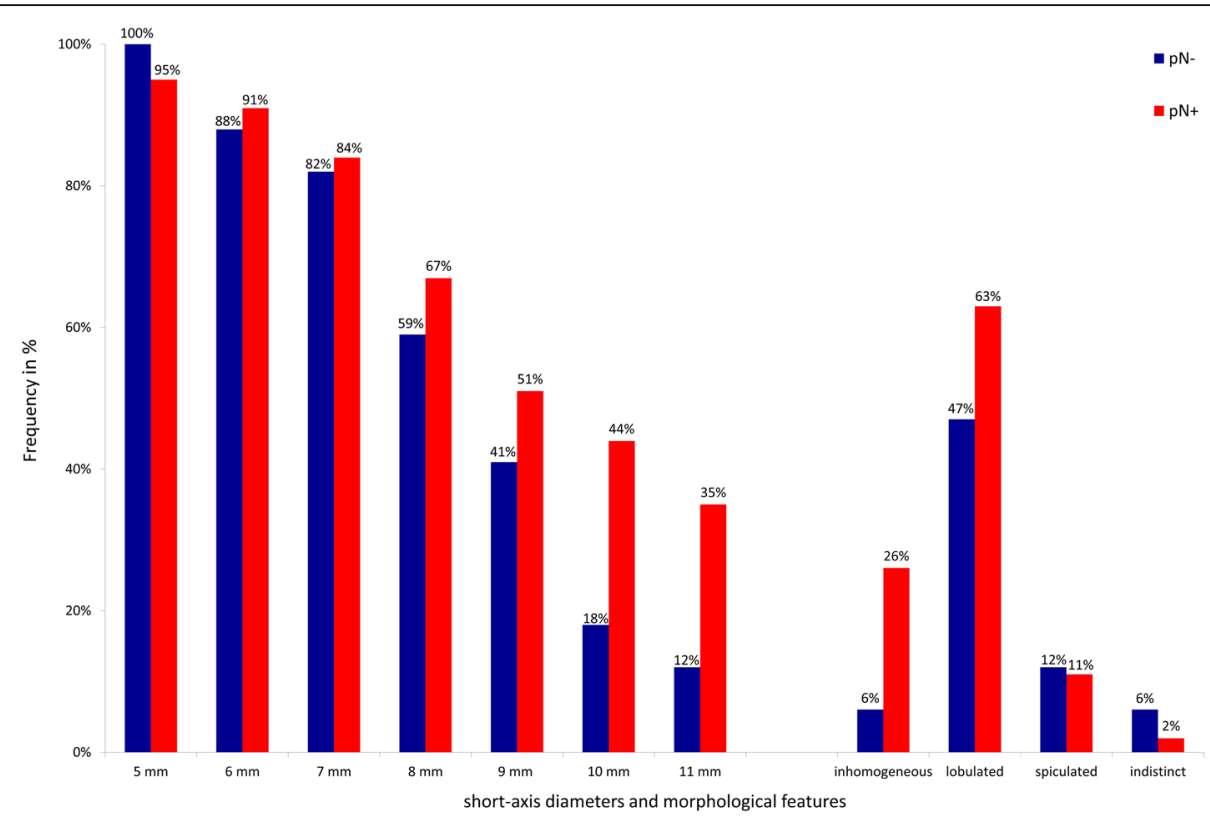

Fig. 3 Graph showing lymph node size and morphological criteria of lymph node-positive and -negative patients. Frequency of regional lymph nodes of the pancreatic head in percent ( $x$-axis) with different short-axis diameters and morphological features ( $y$-axis) in patients with $(p N+$, red bars) or without histologically proven lymph node metastases ( $\mathrm{pN}$-, blue bars) on preoperative CT imaging

\section{Expanded morphological criteria for lymph node involvement on preoperative $\mathrm{CT}$}

Figure 3 shows the percentage of patients with $(\mathrm{pN}+)$ and $(\mathrm{pN}-)$ without lymph node metastases in which a lymph node of the respective morphological criterion was visible and Table 2 shows the sensitivity, specificity, and Youden's Index of the respective criterion.

Lymph nodes of lobulated border contour were visible with a similar frequency in patients with $(63 \% ; 27 / 60$, $\mathrm{pN}+$ ) and without lymph node metastases (47\%; 7/17, $\mathrm{pN}-$ ). Lymph nodes of spiculated or indistinct border contour were only occasionally detected in both groups (11\%; $5 / 43$ vs. $2 \% ; 1 / 43$ in the lymph node-positive group $(\mathrm{pN}+)$ and $12 \% ; 2 / 17$ vs. $12 \% 2 / 17$ in the lymph node-negative group $(\mathrm{pN}-))$.
Lymph nodes of inhomogeneous signal intensity were detected in only one patient of the lymph node-negative group $(6 \% ; 1 / 17, \mathrm{pN}-)$ and more frequently in patients of the lymph node-positive group $(26 \% ; 11 / 43, \mathrm{pN}+)$ resulting in the maximum value of Youden's Index for the morphological criteria $\mathrm{J}=0.20$ (95\% CI; $0.04,0.35$ ), consisting of a sensitivity of $26 \%$ and a specificity of $94 \%$. The PPV was $91.7 \%$.

Comparison of size with expanded morphological criteria The maximum value of the Youden's Index of the "size" criterion was $\mathrm{J}=0.27$ (95\% CI; 0.00, 0.45; cut-off $10 \mathrm{~mm}$ ) which is not inferior to the maximum value of the morphological criteria $J=0.20$ (95\% CI; 0.04, 0.35; inhomogeneous signal intensity). Figure 4 displays respective CT images of patients with and without lymph node metastases.
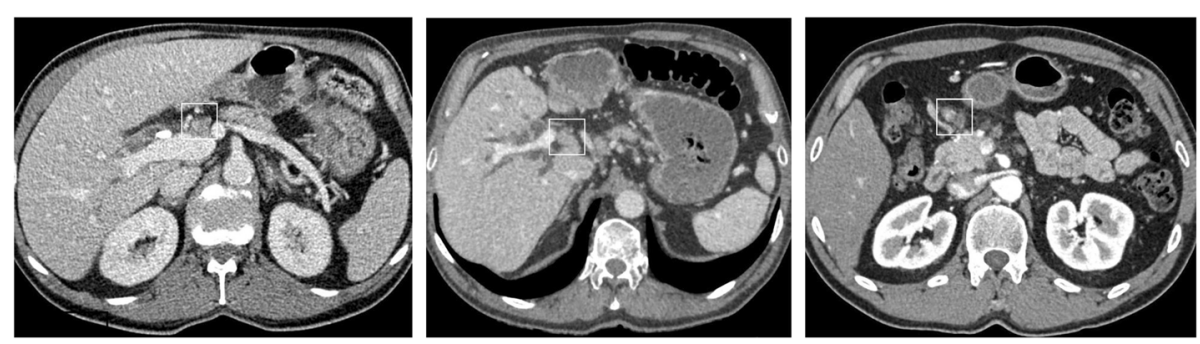

Fig. 4 CT images of patients with and without lymph node metastases. a Patient with enlarged suspicious lymph node adjacent to the portal vein and hepatic artery who had no lymph node metastases on pathology. $\mathbf{b}$ Patient with enlarged suspicious lymph node adjacent to the hepatic artery who had lymph node metastases on pathology. c Patient with multiple suspicious lymph nodes based on size and inhomogeneity who had lymph node metastases on pathology 
Table 2 Sensitivity, specificity, PPV, and Youden's Index for cutoff values and morphological criteria by CT and MRI

\begin{tabular}{|c|c|c|c|c|}
\hline & Sensitivity & Specificity & PPV & Youden's Index \\
\hline \multicolumn{5}{|l|}{$\overline{C T}$} \\
\hline \multicolumn{5}{|l|}{ Size, cut-off value } \\
\hline $4 \mathrm{~mm}$ & $95.3 \%$ & $0 \%$ & $70.7 \%$ & -0.05 \\
\hline $5 \mathrm{~mm}$ & $95.3 \%$ & $0 \%$ & $70.7 \%$ & -0.05 \\
\hline $6 \mathrm{~mm}$ & $90.7 \%$ & $11.7 \%$ & $72.2 \%$ & -0.02 \\
\hline $7 \mathrm{~mm}$ & $83.7 \%$ & $17.6 \%$ & $72.0 \%$ & 0.01 \\
\hline $8 \mathrm{~mm}$ & $67.4 \%$ & $41.2 \%$ & $74.4 \%$ & 0.08 \\
\hline $9 \mathrm{~mm}$ & $51.1 \%$ & $58.8 \%$ & $75.9 \%$ & 0.10 \\
\hline $10 \mathrm{~mm}$ & $44.2 \%$ & $82.4 \%$ & $86.4 \%$ & 0.27 \\
\hline $11 \mathrm{~mm}$ & $34.9 \%$ & $88.2 \%$ & $88.2 \%$ & 0.23 \\
\hline \multicolumn{5}{|c|}{ Morphological criterion } \\
\hline Lobulated & $62.7 \%$ & $52.9 \%$ & $77.1 \%$ & 0.16 \\
\hline Spiculated & $11.6 \%$ & $88.2 \%$ & $71.4 \%$ & -0.00 \\
\hline Indistinct & $2.3 \%$ & $94.1 \%$ & $50.0 \%$ & -0.04 \\
\hline Inhomogeneous & $25.6 \%$ & $94.1 \%$ & $91.7 \%$ & 0.20 \\
\hline \multicolumn{5}{|l|}{ MRI } \\
\hline \multicolumn{5}{|l|}{ Size, cut-off value } \\
\hline $7 \mathrm{~mm}$ & $75.0 \%$ & $0 \%$ & $60.0 \%$ & -0.25 \\
\hline $8 \mathrm{~mm}$ & $58.3 \%$ & $83.3 \%$ & $87.5 \%$ & 0.42 \\
\hline $9 \mathrm{~mm}$ & $58.3 \%$ & $66.7 \%$ & $77.8 \%$ & 0.25 \\
\hline $10 \mathrm{~mm}$ & $58.3 \%$ & $83.3 \%$ & $87.5 \%$ & 0.42 \\
\hline $11 \mathrm{~mm}$ & $25.0 \%$ & $83.3 \%$ & $75.0 \%$ & 0.08 \\
\hline $12 \mathrm{~mm}$ & $16.7 \%$ & $83.3 \%$ & $66.7 \%$ & 0.00 \\
\hline $13 \mathrm{~mm}$ & $16.7 \%$ & $83.3 \%$ & $66.7 \%$ & 0.00 \\
\hline $14 \mathrm{~mm}$ & $8.3 \%$ & $83.3 \%$ & $50.0 \%$ & -0.08 \\
\hline $15 \mathrm{~mm}$ & $8.3 \%$ & $83.3 \%$ & $50.0 \%$ & -0.08 \\
\hline \multicolumn{5}{|c|}{ Morphological criterion } \\
\hline Lobulated & $16.7 \%$ & $66.7 \%$ & $50 \%$ & -0.17 \\
\hline Spiculated & $8.3 \%$ & $100 \%$ & $35.3 \%$ & 0.08 \\
\hline Indistinct & Not visible & & & \\
\hline Inhomogeneous & Not visible & & & \\
\hline
\end{tabular}

\section{Number of visible lymph nodes}

There was a significant association between number of visible lymph nodes seen on preoperative $\mathrm{CT}$ and histopathological lymph node involvement ( $\mathrm{pN}+, \mathrm{p}=0.031)$.

Seven or more lymph nodes were seen on preoperative CT in $32.6 \%(14 / 43)$ of patients with lymph node metastases $(\mathrm{pN}+)$ and in $5.9 \%(1 / 17)$ of patients without lymph node metastasis ( $\mathrm{pN}-, \mathrm{p}=0.046)$. This resulted in a specificity of $94.1 \%$, Youden's Index of 0.27, and PPV of $93.3 \%$.
Combination of number, size, and expanded morphologic criteria on preoperative $\mathbf{C T}$

Combining the size criterion and the morphological criterion with the respective highest Youden's Index (cutoff $10 \mathrm{~mm}$ and "inhomogeneous signal intensity") and the criterion "visible lymph nodes $n \geq 7$ " was significantly associated with nodal metastases $(\mathrm{pN}+, \mathrm{p}=$ 0.004). For this combined criterion, specificity was $82 \%$, sensitivity 61\%, PPV 90\%, and Youden's Index 0.43 (95\% CI; 0.15, 0.60).

\section{Interobserver agreement}

Interobserver agreement was calculated for 20 patients $(\mathrm{pN}+, 75 \% \mathrm{pN}+$ vs. $25 \% \mathrm{pN}-)$ for the criteria size, morphology, and number of visible lymph nodes with the respective highest Youden's Index. Interobserver agreement was substantial for size $(10 \mathrm{~mm}$ cut-off, $\mathrm{\kappa}=$ $0.8, \mathrm{p}=0.001)$, moderate for the presence of seven or more lymph nodes $(\kappa=0.571, \mathrm{p}=0.032)$, and fair for the morphological criterion inhomogeneous signal intensity $(\mathrm{k}=0.306, \mathrm{p}=0.202)$.

\section{Magnetic resonance imaging (MRI)}

Lymph nodes were detected in $88.9 \%(16 / 18)$ of patients on preoperative MRI. The median number of visible lymph nodes was 3 (range 0-6). There was no significant association between number of visible lymph nodes seen on preoperative MRI and histopathological lymph node involvement $(\mathrm{pN}+, \mathrm{p}=0.682)$.

The smallest visible lymph node was $3.0 \mathrm{~mm}$ of size, whereas the largest measured $16 \mathrm{~mm}$ (short-axis diameter). The mean time between MRI and surgery was 11 days with a median of 7 days (range 1-38).

The cut-off values of the highest diagnostic value were $8 \mathrm{~mm}$ or $10 \mathrm{~mm}$ for the "size" criterion (sensitivity $58.3 \%$, specificity $83.3 \%$, Youden's Index $=0.42$ ). The presence of a lymph node of these sizes was not associated with lymph node metastases $(\mathrm{pN}+, \mathrm{p}=0.152)$. Lobulated and spiculated lymph nodes were only seen in a few patients $(n=4$ and $\mathrm{n}=1$ ), and indistinct and inhomogeneous lymph nodes were not seen at all (Table 2).

\section{Discussion}

In this retrospective single-center study on lymph node staging by CT in ductal adenocarcinoma of the pancreatic head, we could show that the morphologic criteria "inhomogeneous signal intensity" and "size" are specific for regional nodal metastatic disease. Replacing the size criterion by morphologic criteria, however, did not improve diagnostic accuracy due to sensitivity remaining low. Combining specific criteria yields improved sensitivity with specificity remaining high.

By CT, lymph nodes of 4-9 $\mathrm{mm}$ in short-axis diameter were seen just as often in patients with and without 
lymph node metastases resulting in poor discrimination. Larger lymph nodes $(>9 \mathrm{~mm})$ had a higher prevalence in the lymph node-positive group leading to high specificity. However, these lymph nodes $(10 \mathrm{~mm}$ or $11 \mathrm{~mm})$ were seen infrequently resulting in a rather low sensitivity. The maximum value of the Youden's Index for the size criterion of 0.27 was achieved when a cut-off value of $10 \mathrm{~mm}$ was applied, consisting of a specificity of $82.4 \%$ and sensitivity of $44.2 \%$, yielding a PPV of $84.6 \%$.

As for morphologic criteria, lymph nodes of lobulated border contour were seen in about half of the patients of both groups ( $\mathrm{pN}+, 63 \%$ and $\mathrm{pN}-, 47 \%$ ), and therefore is a criterion that is not suitable to differentiate between the groups. Lymph nodes of spiculated and indistinct border contour were seen in few cases in both patient groups only ( $\mathrm{pN}+11 \%$ and $2 \%$ versus $\mathrm{pN}-12 \%$ and $6 \%$ ) making them poor diagnostic criteria. However, lymph nodes of inhomogeneous signal intensity were visible in $26 \%$ of patients with lymph node metastases $(\mathrm{pN}+)$ and only in $6 \%$ of the patients without lymph node metastases (pN-), resulting in a Youden's Index of 0.20, which was the maximum value for the morphological criteria, and a PPV of $91.7 \%$.

Ideally, a good discriminator for nodal metastases is negative in patients without nodal involvement and positive for tumors with lymph node metastases. In our study, each criterion, i.e., size as well as different morphological features, only met one of these prerequisites. The size criterion $(10 \mathrm{~mm})$ as well as the presence of a lymph node of inhomogeneous signal intensity as morphological criterion turned out to be negative in patients without nodal involvement ( $\mathrm{pN}-$ ) and therefore highly specific. Yet, lymph nodes of the respective characteristic were not positive in a sufficiently high number of tumors with lymph node metastases $(\mathrm{pN}+)$ to reach high levels of sensitivity and consequently did not have a significant diagnostic value.

The maximum value of the Youden's Index for the size criterion was 0.27 when a cut-off value of $10 \mathrm{~mm}$ was applied and 0.20 for the morphological criteria, when the criterion "inhomogeneous signal intensity" was used, showing that morphologic criteria do not yield in higher diagnostic value than lymph node size in adenocarcinoma of the pancreatic head (PDAC) patients. This is contrary to the findings of Brown et al. in rectal cancer [16]. One reason might be that Brown et al. used MRI to assess morphologic criteria which has a higher soft tissue contrast compared to CT which was used in most patients in our study.

Interestingly, we could show that with preoperative $\mathrm{CT}$, the presence of seven or more lymph nodes was seen more often in patients with lymph node metastasis $(\mathrm{pN}+)$ than in those without metastasis $(\mathrm{pN}-, \mathrm{p}=0.046)$. When applying this as a sole criterion $(\mathrm{cN})$ for lymph node metastasis $(\mathrm{pN})$, this led to a sensitivity of $32.6 \%$, a specificity of $94.1 \%$, PPV of 93.3\%, and Youden's Index of 0.27 .

In diagnostic test analysis, criteria can be combined in mainly two ways: sensitive criteria can be taken together to improve specificity or specific criteria can be accumulated to improve sensitivity. When combining the highly specific criteria size (cut-off value 10 $\mathrm{mm}$ ), inhomogeneous signal intensity, and number of visible lymph nodes $n \geq 7$, a highly significant association with nodal metastases $(\mathrm{pN}+, \mathrm{p}=0.004)$ was found. Consequently, the CT examination was considered node-positive $(\mathrm{cN}+)$ when at least one of these criteria was met. The application of this criterion improved the sensitivity to $60 \%$ with a remaining specificity of $82 \%$ and PPV $90 \%$ resulting in an also improved Youden's Index of 0.43.

The results of the MRI examinations must be viewed in a rather descriptive manner since the sample size was limited ( $\mathrm{n}=18)$. Lymph nodes were detected in the majority $(88.9 \%)$ of examinations generally allowing the evaluation of lymph nodes by MRI as well. Upper abdominal MRI generally has a lower spatial resolution, but a higher soft tissue contrast compared to CT. For the size criterion a cut-off value of $8 \mathrm{~mm}$ or $10 \mathrm{~mm}$ led to the best diagnostic results (sensitivity $58.3 \%$, specificity $83.3 \%$, Youden's Index $=0.42$ ). Lymph nodes of abnormal morphological criteria were seen in only very few patients (Table 2).

The main limitation of this study is the retrospective study design in which a node-by-node comparison of cross-sectional imaging with histopathology was not possible. This was of minor importance, though, since low sensitivity was the main factor that led to compromised diagnostic performance in our study. We were also able to correlate with postoperative cross-sectional imaging in all cases in which it was unclear whether a lymph node had been resected during surgery or not. Also, in our cohort, only patients who had subsequent surgery were included, presuming lower tumor stage as compared to the average patient who undergoes imaging for presurgical workup.

The strength of our single-center study is reinforced by a defined number of surgeons, a high standardization of the CT technique, and an experienced radiologist who performed the analysis.

The results of our study are consistent with recent and initial data demonstrating that clinical staging, by low sensitivity, underestimates histopathological lymph node involvement $(\mathrm{pN}+)[6,20-22]$. However, by adding the criterion "inhomogeneous signal intensity" and "number of visible lymph nodes" to the size criterion, we were able to increase the sensitivity to $60 \%$ in comparison to previous findings (14\%, Roche et al.; 37\% Nanashima 
et al.; and $46.2 \%$, Cao et al.) with specificity remaining sufficient.

An additional imaging modality that has shown the potential to improve the sensitivity of detecting metastatic disease is positron emission tomography-computed tomography (PET/CT) [23]. However, a beneficial role of $\mathrm{PET} / \mathrm{CT}$ in locoregional nodal staging could not be established to date. The majority of initial as well as recent studies show very limited sensitivities for nodal status between 10 and 61\% [24-29]. The PET-PANC study evaluated the incremental diagnostic accuracy and impact of $\mathrm{PET} / \mathrm{CT}$ in addition to multidetector CT in patients with suspected pancreatic cancer in a prospective multicenter study that included 550 patients. In this study, significantly more patients with stage IIb disease $(\mathrm{pN}+)$ were correctly staged by PET/CT than by multidetector CT $(\mathrm{p}=0.002)$, but this only led to a moderate sensitivity of $38 \%$ for PET/ CT versus $22 \%$ for multidetector CT [30].

Endoscopic ultrasonography (EUS) is a well-established diagnostic procedure in pancreatic cancer with the benefit of a dynamic diagnostic examination that allows fineneedle aspiration for cytologic diagnosis. Two metaanalyses evaluating diagnostic accuracy of EUS for locoregional nodal staging the pooled sensitivities and specificities were 0.62 and $0.74(\mathrm{Li}$ et al 2014, 14 studies, $\mathrm{n}=516$ patients) [31] and 69\% and 81\% (Nawaz et al., 16 studies, $\mathrm{n}=512$ patients) [32]. Advanced techniques such as contrast-enhanced EUS (CH-EUS) and EUS elastography are currently in evaluation [33].

To date, CT remains the standard staging imaging modality recommended by NCCN guidelines for locoregional staging of pancreatic cancer [34]. Neither PET/CT nor EUS yields reliable diagnostic accuracy for nodal staging.

An advantageous effect on resectability and overall survival (OS) in unresectable cases (including both borderline resectable and unresectable) of PDAC by multimodality therapy including neoadjuvant therapy has already been described in several studies [35].

The benefit of neoadjuvant therapy in cases of primarily resectable disease at diagnosis is yet less revealed. Several phase II trials showed that patients who completed neoadjuvant chemoradiation without progressive disease at restaging had a higher chance of achieving R0 resection and, consequently, higher median and OS when compared to historical data [36]. As seen in other tumor entities, a potential benefit of neoadjuvant therapy on the basis of positive nodal status $\left(\mathrm{cN}_{+}\right)$is strongly implied. Cao et al. found that the $38 \%$ of patients that were successfully downstaged from node-positive disease (cN1) to node-negative disease (ypN0) by neoadjuvant therapy benefit in terms of higher rates of 5-year survival (ypN0 27.2\% vs ypN1 12.3\%, p < 0.001) [8]. This is consistent with the findings of Portuondo et al. (5-year survival ypN0 $12.4 \%$ vs. ypN1 $6.0 \%, \mathrm{p}<0.0001$ ) [37]. The NCCN guidelines for pancreatic adenocarcinoma appreciates these results by stating that consideration can be given to neoadjuvant therapy for selected patients with resectable tumor but poor prognostic features such as large regional lymph nodes, markedly elevated CA 199, large primary tumors, extreme pain, and excessive weight loss [34]. Further clarification on this matter is expected to come from the ongoing NEONAX trial (NCT02047513), a phase II study comparing neoadjuvant plus adjuvant with only adjuvant nab-paclitaxel plus gemcitabine therapy for resectable pancreatic cancer. The ongoing phase III NEOPA trial (NCT01900327) compares neoadjuvant chemoradiotherapy with upfront surgery of resectable pancreatic head cancer. A subgroup analysis in terms of nodal status would present reliable data.

Given the suggested benefit of neoadjuvant therapy based on lymph node staging, there is an urgent need to find criteria and modalities to further improve the diagnostic value of lymph node staging by pretherapeutic cross-sectional imaging in patients with ductal adenocarcinoma of the pancreatic head. To date, none of the existing modalities and criteria accomplishes reliable nodal staging. Larger, prospective studies are ongoing and necessary to get a more precise idea of the prognostic advantage of neoadjuvant therapy in patients with regional lymph node metastasis $\left(\mathrm{cN}_{+}\right)$of PDAC in pretherapeutic staging.

\section{Conclusions}

Lymph node staging in PDAC patients when using CT morphological criteria such as border contour or homogeneity compared to diameter cut-off values does not lead to reliable diagnostic value. Diagnostic accuracy is limited due to low sensitivity for detection of metastatic disease. Combining specific criteria yields improved sensitivity with specificity and PPV remaining high. These results suggest an attentive interpretation of the results of pretherapeutic lymph node staging, particularly in cases in which lymph node metastases are absent.

\section{Abbreviations \\ PDAC: Adenocarcinoma of the pancreatic head; CT: Computed tomography; MRI: Magnetic resonance imaging; $\mathrm{pN}+$ : Histopathologically involved lymph nodes; pN-: Histopathologically no involved lymph nodes; $\mathrm{CN}+$ : Clinically involved lymph nodes; $\mathrm{CN}$-: Clinically no involved lymph nodes; PPV: Positive predictive value; PET/CT: Positron emission tomography-computed tomog- raphy; EUS: Endoscopic ultrasonography; CH-EUS: Contrast-enhanced endoscopic ultrasonography; OS: overall survival}

\section{Acknowledgements}

We acknowledge support from the German Research Foundation (DFG) and the Open Access Publication Funds of Charité - Universitätsmedizin Berlin.

\section{Authors' contributions}

All authors were involved in data acquisition and manuscript revision. The conception of the design of the study and drafting of the manuscript was 
done by FN Loch, C Kamphues, and P Asbach. Image analysis was performed by $\mathrm{P}$ Asbach and assisted by FN Loch. Image analysis of the subgroup for analysis of interobserver agreement was performed by M Haas. All authors have approved the submitted version of the manuscript and account for their own contribution and the accuracy as well as the integrity of the work presented.

\section{Funding}

The study was not funded.

\section{Availability of data and materials}

The datasets used during the current study are available from the corresponding author on reasonable request.

\section{Ethics approval and consent to participate}

The study was approved by the local ethics committee of the Charité, University Medicine Berlin. Informed consent of participation was waived by the IRB given the retrospective study design (IRB No. EA4/114/18).

\section{Consent for publication}

Consent for publication is not applicable for this study.

\section{Competing interests}

The authors declare that they have no competing interests.

\section{Author details}

${ }^{1}$ Charité - Universitätsmedizin Berlin, corporate member of Freie Universität Berlin, Humboldt-Universität zu Berlin, and Berlin Institute of Health, Department of Surgery, Campus Benjamin Franklin, Hindenburgdamm 30, 12203 Berlin, Germany. ${ }^{2}$ Charité - Universitätsmedizin Berlin, corporate member of Freie Universität Berlin, Humboldt-Universität zu Berlin, and Berlin Institute of Health, Department of Radiology, Campus Benjamin Franklin, Hindenburgdamm 30, 12203 Berlin, Germany. ${ }^{3}$ The Johns Hopkins University School of Medicine, Department of Surgery, 600 N. Wolfe Street, Blalock 688, Baltimore, MD 21287, USA

\section{Received: 12 December 2019 Accepted: 7 July 2020}

\section{Published online: 18 August 2020}

\section{References}

1. Pietryga JA, Morgan DE. Imaging preoperatively for pancreatic adenocarcinoma. J Gastrointest Oncol. 2015:6:343-57.

2. Howlader N, Noone AM, Krapcho M, Garshell J, Miller D, Altekruse SF et al. SEER Cancer Statistics Review, 1975-2012, National Cancer Institute. Bethesda, MD, https://seer.cancer.gov/archive/csr/1975_2012/, based on November 2014 SEER data submission, posted to the SEER web site, April 2015. Section 22, page 8

3. Du T, Bill KA, Ford J, Barawi M, Hayward RD, Alame A, et al. The diagnosis and staging of pancreatic cancer: A comparison of endoscopic ultrasound and computed tomography with pancreas protocol. Am J Surg. 2018;215: $472-5$.

4. Zhang Q, Zeng L, Chen Y, Lian G, Qian C, Chen S, et al. Pancreatic cancer epidemiology, detection, and management. Gastroenterol Res Pract. 2016; 2016:1-10.

5. Yeo CJ, Cameron JL, Lillemoe KD, Sitzmann JV, Hruban RH, Goodman SN, et al. Pancreaticoduodenectomy for cancer of the head of the pancreas. 201 patients. Ann Surg. 1995;221:721-33.

6. Asano T, Hirano S, Nakamura T, Okamura K, Tsuchikawa T, Noji T, et al. Survival benefit of conversion surgery for patients with initially unresectable pancreatic cancer who responded favorably to nonsurgical treatment. J Hepato-Biliary-Pancreat Sci. 2018;25:342-50.

7. Endo Y, Kitago M, Aiura K, Shinoda M, Yagi H, Kitagawa Y, et al. Efficacy and safety of preoperative 5-fluorouracil, cisplatin, and mitomycin $C$ in combination with radiotherapy in patients with resectable and borderline resectable pancreatic cancer: a long-term follow-up study. World J Surg Onc. 2019:17:145-152 27

8. Cao HST, Zhang Q, Sada YH, Silberfein EJ, Hsu C, Van Buren G, et al. Value of lymph node positivity in treatment planning for early stage pancreatic cancer. Surgery. 2017;162:557-67.
9. Zeman RK, Cooper C, Zeiberg AS, Kladakis A, Silverman PM, Marshall JL, et al. TNM staging of pancreatic carcinoma using helical CT. Am J Roentgenol. 1997;169:459-64.

10. Müller MF, Meyenberger C, Bertschinger P, Schaer R, Marincek B. Pancreatic tumors: evaluation with endoscopic US, CT, and MR imaging. Radiology. 1994;190:745-51.

11. Midwinter MJ, Beveridge CJ, Wilsdon JB, Bennett MK, Baudouin CJ, Charnley RM. Correlation between spiral computed tomography, endoscopic ultrasonography and findings at operation in pancreatic and ampullary tumours. Br J Surg. 1999;86:189-93.

12. Rösch T, Braig C, Gain T, Feuerbach S, Siewert JR, Schusdziarra V, et al. Staging of pancreatic and ampullary carcinoma by endoscopic ultrasonography: Comparison with conventional sonography, computed tomography, and angiography. Gastroenterology. 1992;102:188-99.

13. Prenzel KL, Hölscher AH, Vallböhmer D, Drebber U, Gutschow CA, Mönig SP, et al. Lymph node size and metastatic infiltration in adenocarcinoma of the pancreatic head. Eur J Surg Oncol. 2010;36:993-6.

14. Rollvén E, Blomqvist L, Öistämö E, Hjern F, Csanaky G, Abraham-Nordling M. Morphological predictors for lymph node metastases on computed tomography in colon cancer. Abdom Radiol. 2019;44:1712-21.

15. Brown G, Richards CJ, Bourne MW, Newcombe RG, Radcliffe AG, Dallimore NS, et al. Morphologic predictors of lymph node status in rectal cancer with use of high-spatial-resolution MR imaging with histopathologic comparison. Radiology. 2003;227:371-7

16. Kim JH, Beets GL, Kim MJ, Kessels AGH, Beets-Tan RGH. High-resolution MR imaging for nodal staging in rectal cancer: are there any criteria in addition to the size? Eur J Radiol. 2004;52:78-83.

17. Isaji S, Murata Y, Kishiwada M. New Japanese classification of pancreatic cancer. In: Neoptolemos J, Urrutia R, Abbruzzese J, Büchler MW, editors. Pancreatic Cancer. New York: Springer; 2017. p. 1-17.

18. Brierley JD, Gospodarowicz MK, Wittekind C. UICC: TNM Classification of Malignant Tumours. 8th ed. Oxford: Wiley-Blackwell; 2017. p. 93-6.

19. Youden WJ. Index for rating diagnostic tests. Cancer. 1950;3:32-5.

20. Swords DS, Firpo MA, Johnson KM, Boucher KM, Scaife CL, Mulvihill SJ. Implications of inaccurate clinical nodal staging in pancreatic adenocarcinoma. Surgery. 2017:162:104-111. 28.

21. Nanashima A, Sakamoto I, Hayashi T, Tobinaga S, Araki M, Kunizaki M, et al. Preoperative diagnosis of lymph node metastasis in biliary and pancreatic carcinomas: Evaluation of the combination of multi-detector CT and serum CA19-9 level. Dig Dis Sci. 2010:55:3617-26.

22. Roche CJ, Hughes ML, Garvey CJ, Campbell F, White DA, Jones L, et al. CT and pathologic assessment of prospective nodal staging in patients with ductal adenocarcinoma of the head of the pancreas. AJR Am J Roentgenol. 2003;180:475-80.

23. Farma JM, Santillan AA, Melis M, Walters J, Belinc D, Chen DT, et al. PET/CT fusion scan enhances $C T$ staging in patients with pancreatic neoplasms. Ann Surg Oncol. 2008;15:2465-71.

24. Kauhanen SP, Komar G, Seppänen MP, Dean KI, Minn HR, Kajander SA, et al. A prospective diagnostic accuracy study of 18F-fluorodeoxyglucose positron emission tomography/computed tomography, multidetector row computed tomography, and magnetic resonance imaging in primary diagnosis and staging of pancreatic cancer. Ann Surg. 2009;250: 957-63.

25. Lemke AJ, Niehues SM, Hosten N, Amthauer H, Boehmig M, Stroszczynski C, et al. Retrospective digital image fusion of multidetector $C T$ and 18F-FDG PET: clinical value in pancreatic lesions-a prospective study with 104 patients. J Nucl Med. 2004;45:1279-86.

26. Heinrich S, Goerres GW, Schäfer M, Sagmeister M, Bauerfeind P, Pestalozzi $\mathrm{BC}$, et al. Positron emission tomography/computed tomography influences on the management of resectable pancreatic cancer and its costeffectiveness. Ann Surg. 2005:242:235.

27. Joo I, Lee JM, Lee DH, Lee ES, Paeng JC, Lee SJ, et al. Preoperative assessment of pancreatic cancer with FDG PET/MR imaging versus FDG $\mathrm{PET} / \mathrm{CT}$ plus contrast-enhanced multidetector CT: a prospective preliminary study. Radiology. 2017;282:149-59.

28. Asagi A, Ohta K, Nasu J, Tanada M, Nadano S, Nishimura R, et al. Utility of contrast-enhanced FDG-PET/CT in the clinical management of pancreatic cancer: impact on diagnosis, staging, evaluation of treatment response, and detection of recurrence. Pancreas. 2013;42:11-9.

29. Kim HR, Seo M, Nah YW, Park HW, Park SH. Clinical impact of fluorine-18fluorodeoxyglucose positron emission tomography/computed tomography 
in patients with resectable pancreatic cancer: diagnosing lymph node metastasis and predicting survival. Nucl Med Commun. 2018;39(7):691-8.

30. Ghaneh P, Hanson R, Titman A, Lancaster G, Plumpton C, Lloyd-Williams H, et al. PET-PANC: multicentre prospective diagnostic accuracy and health economic analysis study of the impact of combined modality 18fluorine-2fluoro-2-deoxy-d-glucose positron emission tomography with computed tomography scanning in the diagnosis and management of pancreatic cancer. Health Technol Assess. 2018;22:1-114.

31. Li JH, He R, Li YM, Cao G, Ma QY, Yang WB. Endoscopic ultrasonography for tumor node staging and vascular invasion in pancreatic cancer: a metaanalysis. Digest Surg. 2014;31:297-305.

32. Nawaz H, Yi-Fan C, Kloke J, Khalid A, McGrath K, Landsittel D, et al. Performance characteristics of endoscopic ultrasound in the staging of pancreatic cancer: a meta-analysis. JOP. 2013;14:484.

33. Kitano M, Yoshida T, Itonaga M, Tamura T, Hatamaru K, Yamashita Y. (2019). Impact of endoscopic ultrasonography on diagnosis of pancreatic cancer. J Gastroenterol. 2019;54:19-32.

34. Network NCC. NCCN guidelines version 1.2020. Pancreatic Adenocarcinoma. https://www.nccn.org/professionals/physician_gls/pdf/pancreatic.pdf.

35. Laurence JM, Tran PD, Morarji K, Eslick GD, Lam VWT, Sandroussi C. A systematic review and meta-analysis of survival and surgical outcomes following neoadjuvant chemoradiotherapy for pancreatic cancer. J Gastrointest Surg. 2011;15:2059-69.

36. Lim KH, Chung E, Khan A, Cao D, Linehan D, Ben-Josef E, et al. Neoadjuvant therapy of pancreatic cancer: the emerging paradigm? Oncologist. 2012;17: 192-200.

37. Portuondo Jl, Massarweh NN, Zhang Q, Chai CY, Cao HST. Nodal downstaging as a treatment goal for node-positive pancreatic cancer. Surgery. 2019;165:1144-50.

\section{Publisher's Note}

Springer Nature remains neutral with regard to jurisdictional claims in published maps and institutional affiliations.

Ready to submit your research? Choose BMC and benefit from:

- fast, convenient online submission

- thorough peer review by experienced researchers in your field

- rapid publication on acceptance

- support for research data, including large and complex data types

- gold Open Access which fosters wider collaboration and increased citations

- maximum visibility for your research: over $100 \mathrm{M}$ website views per year

At $\mathrm{BMC}$, research is always in progress.

Learn more biomedcentral.com/submissions 